\title{
Applications of nanomaterials for future food security: challenges and prospects
}

\author{
Md. Tofazzal Islam
}

Department of Biotechnology, Bangabandhu Sheikh Mujibur Rahman Agricultural University, Gazipur 1706, Bangladesh, e-mail: tofazzalislam@yahoo.com

\section{Doi : 10.2478/mjhr-2019-0002}

Nanotechnology involves manufacture, manipulation, and application of nanoparticles [1]. The nanoparticles are fine materials prepared from the assembly of atoms or molecules at the size dimension ranging from 1 to $100 \mathrm{~nm}$ [2]. These diversely ultrastructured particles have unique properties such as size-dependent qualities, high surface-to-volume ratio and unique optical properties at a critical length scale [3,4]. However, the US Department of Agriculture defined nanoparticles from the point of view of agriculture as "particulate between 10 and 1,000 nm in size dimensions that are simultaneously colloidal particulate" [5]. The nanotechnology is now considered as one of the key enabling technologies for $21^{\text {st }}$ century that remarkably contribute to sustainable competitiveness and growth in several industrial sectors such as electronics, material science, energy sectors, medicine, biotechnology, and agriculture [6].

The technologies used in 'green revolution' hugely helped us to feed billions of populations and avoid famine mostly in Asia and Africa. However, the very high input-based crop production that led to green revolution seem now unsustainable to meet the growing demand of food for increasing world population, high production cost, and the deleterious effects of the agrochemical inputs to the environment. On the other hand, the world population is expected to increase from 7.3 to 9.7 billion by 2050. Pest outbreak and increased abiotic stresses due to climate change pose a high risk to future crop production. To keep up with the pace of population growth, it has been estimated that food production will need to be increased by $70-100 \%$ by 2050 for a well-fed world population $[7,8]$. To meet this predicted demand of food production, application of novel and smart technologies including genome editing of crop plants using CRISPR (l) (CRISPR-associated enzyme) and nanobiotechnology are needed to address new challenges in agriculture in the next decades on an urgent basis [9].

Nanotechnology is emerged as one of the smart technologies that have high potential to augment agricultural productivity and food security in various ways. Application of nanomaterials can be used for dramatically improve plant nutrition, plant protection, improvement of soil and environmental health, promotion of plant growth, crop improvement, food processing, water management, disease diagnosis, food packaging, abiotic stress tolerance, and precision agriculture (Fig. 1). For example, novel nanoformulation of pesticide can remarkably improve the efficacy and safety of pesticides for plant protection [10]. Similarly, nanofertilizers show low movement and slow rate of degradability and thus remarkably improves the efficiency of used fertilizer $[11,12]$. Application of nanofertilizer or fertilizer element(s) in the nanocarrier improve growth and productivity of crops. Potentials of nanomaterials for sustainable plant nutrition and crop production have been reviewed [11]. Recently, daylight-driven rechargeable antimicrobial nanofibrous membranes (RNMs) were developed by incorporating daylight-active chemicals that can effectively and efficiently produce reactive oxygen species (ROS) to ward-off bacterial and fungal pathogens of infectious diseases [13]. This exciting strategy of the production of antimicrobial nanomaterials could be useful for preparation of highly efficient and targetoriented nanopesticides to promote sustainable agriculture. Devices and tools of nanotechnology such as nanocapsules, nanoparticles and even viral capsids, are found useful for precise detection and treatment of diseases, the enhancement of nutrient absorption by plants, the delivery of active ingredients to specific sites, and improvement of water treatment processes. Nanomaterials are also found useful in the field of plant breeding and genetic transformation. The potential of nanoparticles to overcome bottlenecks in conventional gene delivery makes them more efficient candidates for delivery 
of nuclease-based genome editing cargo. Thus, nanoparticle delivery seems a critical technology for the advancement of genetic engineering of plants including genome editing [14,15].

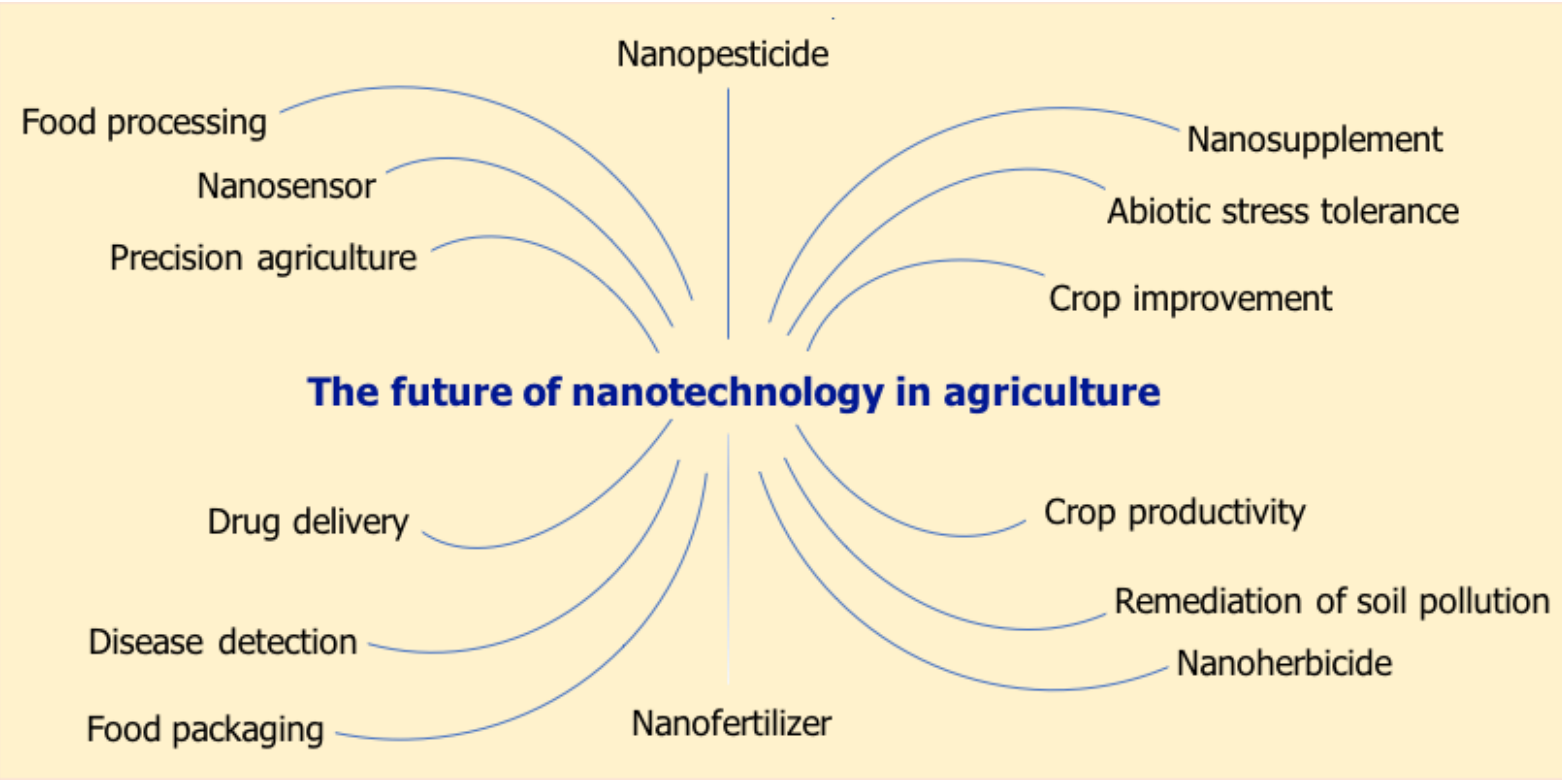

Fig. 1. Application of nanomaterials in agriculture.

The prospect of the application of nanomaterials for augmenting agricultural productivity is very high. However, there are a few challenges that need to be addressed, for example, increasing the scale of production processes, decreasing costs, and thorough assessment of potential hazards before commercialization of any nanomaterials in agriculture. The nanoparticles derived from biomolecules such as proteins and carbohydrates having low deleterious effects on human health and the environment are attractive candidates in these aspects. For example, the potential of starch-based nanoparticles as nontoxic and sustainable delivery systems for fertilizers, pesticides and biostimulants have been found highly promising. Recently developed nanomaterials and nanostructures have unique chemical, physical, and mechanical properties.These interesting nanomaterials areelectrochemically active carbon nanotubes, nanofibers and fullerenes havepotential applications for highly sensitive biochemical sensors. These nanosensors could largely be used for efficient soil analysis, easy bio-chemical sensing and control, water management and delivery, pesticide and nutrient delivery [6]. Another exciting area of nanotechnology is to utilize agricultural waste to prepare high-valued materials and renewable energy [16]. The priority areas of research and applications of nanomaterials in the developing countries should be plant nutrition, crop protection, epidemiology and forecasting, disease diagnosis, biotechnology, healthcare of animals, food processing and packaging, water useefficiency (irrigation) and precision farming. However, the major factors limiting the development of these applications are poor capacities and low investments in building capacities for nanotechnology research.

Although nanotechnology has tremendous potentials in agriculture, there are some bottlenecks in their practical application especially in the developing countries. These challenges are as follows. (i) Nanotoxicity - some nanomaterials have shown to alter gene expression, DNA damage and increased toxicity to the non-targeted organisms. Therefore, proper safety studies are needed before introduction of a novel nanomaterials in agriculture. (ii) Large-scale production of some nanomaterials is difficult and expensive. (iii) Most of the novel nanomaterials are patented and thus restricts their use. (iv) Unavailability of proper laws and regulations for their application in agriculture. (v) Poor capacities (human resource and infrastructures) in the developing countries for research on nanomaterials. However, all these limitations could easily be overcome if appropriate policy decisions are taken and implemented by the developing countries for the promotion of research and application of nanotechnology in agriculture. 
In conclusion, the new nanomaterials such as nanofertilizers, nanopesticides, nanocarriers, nanosensors, nanopackaging, and nanochips would revolutionize agricultural productivity through smart nutrition, promotion of growth, and protection of crop plants [17]. Nanomaterials could even be used for the management of fearsome emerging diseases of major food crops such as wheat blast [18]. Application of nanomaterials obviously promote precision and smart agriculture and significantly reduce the production cost and post-harvest losses in crop production. New nanoparticles from biomasses such as highly porous nanocarbon from lignocellulosic fiber jute remarkably add high value to the agricultural produces and processed materials [16]. Application of nanomaterialsalso remarkably promote generation of new nanobiotechnology including genetic engineering. However, indiscriminate use of nanomaterials may have detrimental effects on environment (nanotoxicity). Need-based, visionary and co-ordinated interdisciplinary research efforts are needed for the development of novel nanomaterials and their safe and greater application in agriculture for ensuring future food security and sustainability in agriculture.

\section{Acknowledgement}

The author is thankful to the Government of Bangladesh and World Bank for supporting this work through a HEQEP CPSF 2071.

\section{References}

[1] Jiang, B., Li, C., Dag, O., Abe, H., Takei, T., Imai, T., Hossain, M.S.A., Islam, M.T., Wood, K, Henzie, J., Yamauchi, Y. 2017. Mesoporous metallic rhodium nanoparticles. Nature Communications, 8,15581.

[2] Auffan, M., Rose, J., Bottero, JY., Lowry, G.V., Jolivet, J.P., Wiesner, M.R. 2009. Towards a definition of inorganic nanoparticles from an environmental, health and safety perspective. Nature Nanotechnology, 4,634 .

[3] Ghormade, V., Deshpande, M.V., Paknikar, K.M. 2011. Perspectives for nano-biotechnology enabled protection and nutrition of plants. Biotechnology Advances, 29 (6), 792-803.

[4] Ditta, A. 2012. How helpful is nanotechnology in agriculture? Advances in Natural Sciences: Nanoscience and Nanotechnology, 3(3), 033002.

[5] Nakache, E., Poulain, N., Candau, F., Orecchioni, A.M., Irache, J.M. 1999. Biopolymer and polymer nanoparticles and their biomedical applications. In: Nalwa HS, editor. Handbook of Nanostructured Materials and Nanotechnology. New York, NY, USA: Academic Press.

[6] Parisi, C., Vigani, M., Rodríguez-Cerezo, E., 2015. Agricultural nanotechnologies: what are the current possibilities? Nano Today, 10(2), 124-127.

[7] Godfray, H.C., Beddington, J.R., Crute, I.R., Haddad, L., Lawrence, D., Muir, J.F., Pretty, J., Robinson, S., Thomas, S.M., Toulmin, C. 2010. Food security: the challenge of feeding 9 billion people. Science, 327, 812-818.

[8] Jones, J.D., Witek, K., Verweij, W., Jupe, F., Cooke, D., Dorling, S., Tomlinson, L., Smoker, M., Perkins, S., Foster, S. 2014. Elevating crop disease resistance with cloned genes. Philosophical Transactions of The Royal Society B Biological Sciences, 369, 20130087.

[9] Haque, E., Taniguchi, H., Hassan, M.M., Bhowmik, P., Karim, M.R., Smiech, M., ' Zhao, K., Rahman, M. Islam, T. 2018. Application of CRISPR/Cas9 genome editing technology for the improvement of crops cultivated in tropical climates: recent progress, prospects, and challenges. Frontiers in Plant Science, 9, 617. 
[10] Zhao, X., Cui, H., Wang, Y., Sun, C., Cui, B., Zeng, Z. 2017. Development strategies and prospects of nano-based smart pesticide formulation. Journal of Agricultural and Food Chemistry, 66 (26), 65046512.

[11] Ditta, A., Arshad, M. 2016. Applications and perspectives of using nanomaterials for sustainable plant nutrition. Nanotechnology Review, 2(5), 209-229.

[12] Kah, M., Kookana, R.S., Gogos, A., Bucheli, T.D. 2018. A critical evaluation of nanopesticides and nanofertilizers against their conventional analogues. Nature Nanotechnology, 13, 677-684.

[13] Si, Y., Zhang, Z., Wu, W., Fu, Q., Huang, K., Nitin, N., Ding, B., Sun, G. 2018. Daylight-driven rechargeable antibacterial and antiviral nanofibrous membranes for bioprotective applications. Science Advances, 4(3), eaar5931.

[14] Cunningham, F.J., Goh, N.S., Demirer, G.S., Matos, J.L., Landry, M.P. 2018. Nanoparticle-mediated delivery towards advancing plant genetic engineering. Trends in Biotechnology, 36 (9), 882-897.

[15] Doudna, J.A., Charpentier, E. 2014. The new frontiers of genome engineering with CRISPR-Cas9. Science (November 28) 346, 1077-1087.

[16] Khan, J.H., Lin, J., Young, C., Matsagar, B.M., Wu, K.C., Dhepe, P.L., Islam, M.T., Rahman, M., Shrestha, L.K., Alshehri, S.M., Ahamad, T. 2018. High surface area nanoporous carbon derived from Bangladeshi jute. Materials Chemistry and Physics, 216(1), 491-495.

[17] Islam, M.S., Akter, N., Rahman, M.M., Shi, C., Islam, M.T., Zeng, H., Azam, M.S. 2018. Mussel-inspired immobilization of silver nanoparticles toward antimicrobial cellulose paper. ACS Sustainable Chemistry \& Engineering, 6(7), 9178-9188.

[18] Islam, M.T., Croll, D., Gladieux, P., Soanes, D.M., Persoons, A., Bhattacharjee, P., Hossain, M.S., Gupta, D.R., Rahman, M.M., Mahboob, M.G., Cook, N., Salam, M.U., Surovy, M.S., Sancho, V. B., Maciel, J.L.N., Júnior, A.N., Castroagudín, V.L., Reges, J.T.A., Ceresini, P.C., Ravel, S., Kellner, R., Fournier, E., Thareau, D., Lebrun, M.H., McDonald, B.A., Stitt, T., Swan, D., Talbot, N.J., Saunders, D.G.O., Win, J., Kamoun, S. 2016. Emergence of wheat blast in Bangladesh was caused by a South American lineage of Magnaporthe oryzae. BMC Biology 14, 84 . 